\title{
Long-acting reversible contraception use among residents in obstetrics/gynecology training programs
}

This article was published in the following Dove Press journal:

Open Access Journal of Contraception

10 January 2017

Number of times this article has been viewed

\author{
Rachel E Zigler' \\ Jeffrey F Peipert ${ }^{1,2}$ \\ Qiuhong Zhao' \\ Ragini Maddipati' \\ Colleen McNicholas' \\ 'Department of Obstetrics and \\ Gynecology, Division of Clinical \\ Research and Family Planning, \\ Washington University School of \\ Medicine in St. Louis, St. Louis, MO, \\ ${ }^{2}$ Department of Obstetrics and \\ Gynecology, Indiana University School \\ of Medicine, Indianapolis, IN, USA
}

Correspondence: Rachel E Zigler Department of Obstetrics and Gynecology, Division of Clinical Research and Family Planning, Washington University in St. Louis, 4533 Clayton Avenue, Campus Box 8219, St. Louis, MO 63II0, USA

Tel +I 3147476409

Fax +I 3147476722

Email ziglerr@wudosis.wustl.edu
Background: The objective of the study was to estimate the personal usage of long-acting reversible contraception (LARC) among obstetrics and gynecology (Ob/Gyn) residents in the United States and compare usage between programs with and without a Ryan Residency Training Program (Ryan Program), an educational program implemented to enhance resident training in family planning.

Materials and methods: We performed a web-based, cross-sectional survey to explore contraceptive use among Ob/Gyn residents between November and December 2014. Thirty-two $\mathrm{Ob} / \mathrm{Gyn}$ programs were invited to participate, and 24 programs (75\%) agreed to participate. We divided respondents into two groups based on whether or not their program had a Ryan Program. We excluded male residents without a current female partner as well as residents who were currently pregnant or trying to conceive. We evaluated predictors of LARC use using bivariate analysis and multivariable Poisson regression.

Results: Of the 638 residents surveyed, $384(60.2 \%)$ responded to our survey and 351 were eligible for analysis. Of those analyzed, 49.3\% (95\% confidence interval [CI]: 44.1\%, 54.5\%) reported current LARC use: $70.0 \%$ of residents in Ryan Programs compared to $26.8 \%$ in nonRyan Programs ( $\mathrm{RR}_{\text {adj }} 2.14,95 \%$ CI 1.63-2.80). Residents reporting a religious affiliation were less likely to use LARC than those who described themselves as non-religious $\left(\mathrm{RR}_{\text {adj }} 0.76\right.$, 95\% CI 0.64-0.92). Of residents reporting LARC use, 91\% were using the levonorgestrel intrauterine device.

Conclusion: LARC use in this population of women's health specialists is substantially higher than in the general population ( $49 \%$ vs. $12 \%$ ). Ob/Gyn residents in programs affiliated with the Ryan Program were more likely to use LARC.

Keywords: contraception, education, family planning, LARC, Ob/Gyn residents

\section{Introduction}

Long-acting reversible contraception (LARC) methods are the most effective reversible methods of pregnancy prevention. ${ }^{1}$ The three commonly used LARC methods available in the United States (US) include the copper and levonorgestrel-containing intrauterine devices (IUDs) and the subdermal etonogestrel implant. LARC uptake has been particularly high within the family planning community, with one study demonstrating $41.7 \%$ of sampled providers using a LARC method. ${ }^{2}$ Uptake in the general population is not nearly as high with recent data demonstrating an increase from $2.4 \%$ in 2002 to $8.5 \%$ in $2009 .{ }^{3}$ These findings were corroborated by the recent data from the National Survey of Family Growth showing that the percentage of women using LARC were stable at $1.5 \%$ from 1988 until 2002 and increased to $7.2 \%$ by $2011 .{ }^{4}$ In 2015, the Guttmacher Institute quoted the most recent rate of LARC use in the US as 
11.6\%. ${ }^{5}$ Low uptake of LARC can be attributed to many factors including cost, patient knowledge and access, and, lastly, provider knowledge and bias. The Contraceptive CHOICE Project demonstrated that when these barriers were removed, LARC uptake could be as high as $75 \% .{ }^{6,7}$ While all forms of contraception are important and should be discussed with patients, improving access to LARC has been identified by the family planning community as one strategy to reduce unintended pregnancy and abortion rates..$^{7-9}$

Obstetrics and gynecology (Ob/Gyn) residents may be among the most educated consumers of evidence-based family planning. Their training focuses on women's health, which specifically includes the provision of contraception. This, in turn, should reflect a highly informed and knowledgeable population of physicians and consumers. However, exposure to contraception is not standardized across residency training programs in the US. In 1999, the Kenneth J. Ryan Residency Training Program (Ryan Program) was launched to integrate and enhance family planning training for $\mathrm{Ob} / \mathrm{Gyn}$ residents in the US and Canada. ${ }^{10}$ The Ryan Program provides an opportunity for $\mathrm{Ob} / \mathrm{Gyn}$ residents to have a structured experience in abortion and contraception education. To date, 80 of the 243 (40\%) US Ob/Gyn residencies have incorporated the Ryan Program. While less than one-half of residencies have a Ryan Program, the Accreditation Council of Graduate Medical Education still requires that $\mathrm{Ob} / \mathrm{Gyn}$ residency programs provide a structured didactic and clinical educational experience in all methods of family planning, including all reversible and permanent methods of contraception. ${ }^{11}$

Our study estimated the personal contraceptive use of $\mathrm{Ob} / \mathrm{Gyn}$ residents in the US and the percentage of residents using the most effective reversible contraceptive methods. We also evaluated the association of formalized contraceptive training through the Ryan Program with the contraceptive choices of current $\mathrm{Ob} / \mathrm{Gyn}$ residents and/or their partners. We hypothesized that a greater percentage of $\mathrm{Ob} / \mathrm{Gyn}$ residents were using LARC methods in comparison to the general population and, secondarily, that residents exposed to the Ryan Program would be more likely to use LARC methods than residents in programs without Ryan training.

\section{Materials and methods}

\section{Study design and data collection}

Between November and December 2014, we performed a nationwide survey of $\mathrm{Ob} / \mathrm{Gyn}$ residents using a convenience sample obtained from the American Congress of Obstetrics and Gynecology website directory (www.acog.org). ${ }^{12}$ The Institutional Review Board of Washington University in
St. Louis approved this study for exempt status prior to participant recruitment. For efficiency, we gave preference to larger programs with a greater number of residents in order to meet our required sample size. Programs were selected based on whether or not they had a Ryan Program. This information was obtained from the Ryan Program website (www.ryanprogram. org). ${ }^{13}$ We attempted to balance the Ryan/non-Ryan groups by geographic region (e.g., Northeast, West, Midwest, etc.). We approached 32 programs ( 3 with religious affiliation, 29 without religious affiliation), and ultimately the web-based survey (developed using Research Electronic Data Capture) was distributed to residents in 24 programs (638 residents out of 5,000 active US residents, $13 \%$ ) after introducing the project to residency coordinators or program directors. ${ }^{14}$ Two electronic invitations were sent to residency coordinators and/ or program directors. Study information and survey links were sent via email to residents by their program coordinator and/ or director. Consent was implied by survey participation as it was described as voluntary. Respondents were compensated with a $\$ 5$ electronic gift card after survey completion.

Our survey took approximately 10 minutes to complete. The survey collected demographic characteristics as well as current relationship status and respondent's religious affiliation. Respondents were asked if they or their partner were currently pregnant or trying to conceive. If the respondent (or the respondent's partner) was not currently pregnant or trying to conceive, she/he was asked about her/his partner's current contraceptive method. Finally, respondents were asked about factors affecting their method of choice.

\section{Data analysis}

We included all respondents in our initial analysis comparing resident characteristics in Ryan versus non-Ryan Programs. However, in our analysis of contraceptive use, we excluded residents who were pregnant or trying to conceive, as well as male respondents without female partners. Female respondents with female partners were included, as our assessment of contraceptive use was not limited to pregnancy prevention.

All statistical analyses were performed using Stata Software (v.11; StataCorp, College Station, Texas, USA). Demographic characteristics were presented as means, standard deviations, and percentages stratified by Ryan Program status. Student's $t$-tests, chi-square tests, and Fisher's exact tests were used where appropriate to compare characteristics of Ryan Program residents to residents from programs without a Ryan. We compared demographic characteristics between respondents using a LARC method and those using a non-LARC method. We evaluated predictors of LARC 
use using bivariate analysis and Poisson regression with robust error variance. This multivariable method provides an unbiased estimate of the relative risk (RR) given a common outcome (greater than 10\%). Significant factors identified in the bivariate analysis were included in the final adjusted multivariable regression model.

We calculated our sample size based on an alpha level of 0.05 and power of $80 \%$. Use of LARC by non-Ryan residents was estimated to be $15 \%$. Assuming a 2 -fold increase in LARC use among Ryan Program residents compared to non-Ryan residents, we needed a sample size of 118 residents per group. Given our sample of more than 180 per group, we had $>90 \%$ power to detect a statistically significant difference (type II error rate $<10 \%$ ).

\section{Results}

Of the $32 \mathrm{Ob} / \mathrm{Gyn}$ residency training programs invited to participate, 11 sites with Ryan Programs and 13 sites without a Ryan Program (total $=24$ programs or $75 \%$ ) agreed to participate. Of the 638 residents in these 24 programs, 384 completed the web-based survey, with a survey response rate of $60.2 \%$.

In our analysis of Ryan versus non-Ryan respondents, we excluded 7 male respondents without female partners. Twentysix participants were also excluded as they were pregnant or trying to conceive. Thus, we were left with an analytic sample of 351 participants (183 participants in Ryan Programs and 168 in non-Ryan Programs; Figure 1). Residents in Ryan and non-Ryan Programs were similar with the exception of

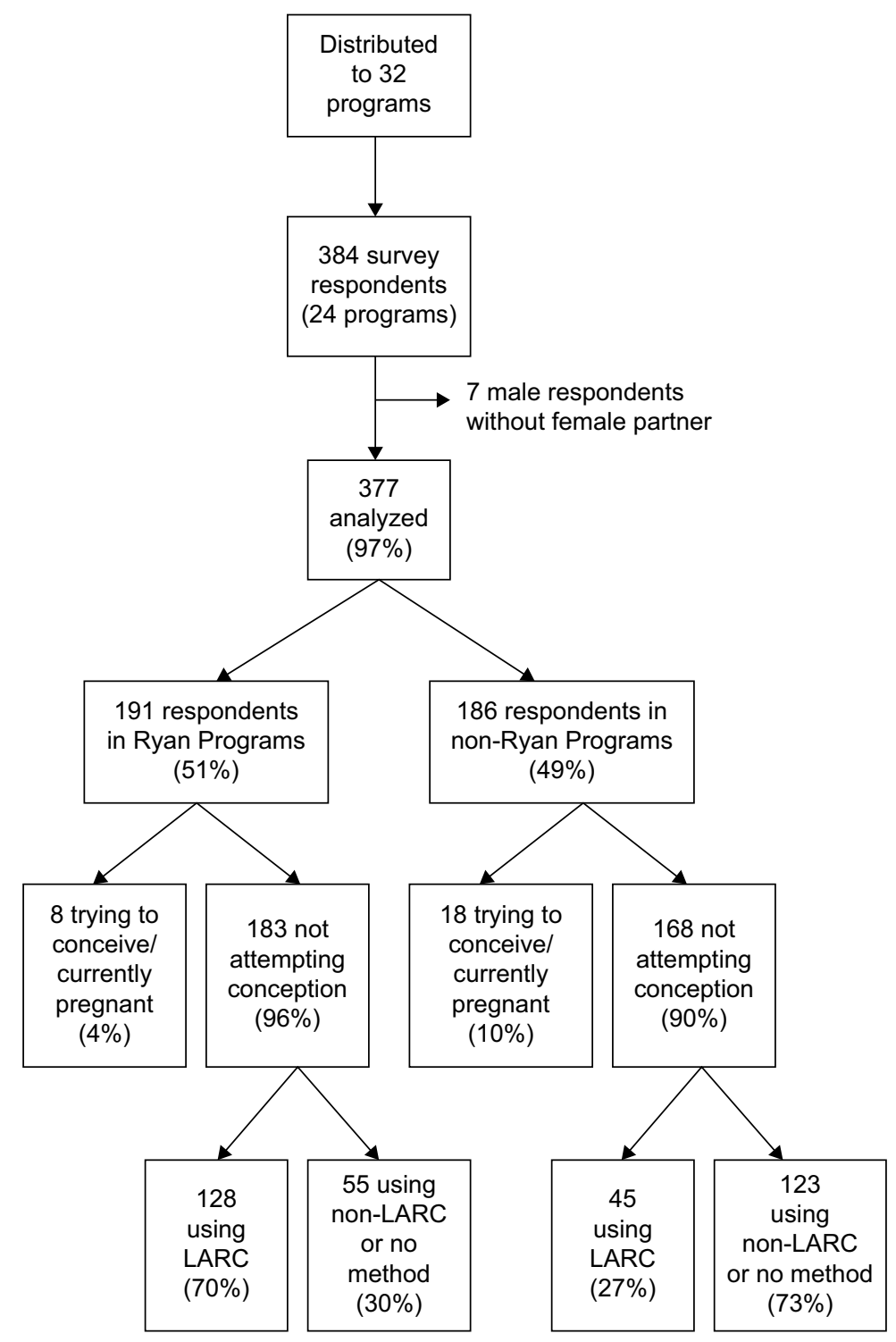

Figure I Participant flow diagram

Abbreviation: LARC, long-acting reversible contraception; Ryan Program, Ryan Residency Training Program. 
reported personal religious affiliation, number of residents pregnant or trying to conceive, and LARC use (Table 1).

Of the eligible respondents, when asked to name their primary method of contraception, $49.3 \%$ (173/351) reported using a LARC method, 43.6\% (153/351) reported using a

Table I Characteristics of residents in Ryan vs. non-Ryan affiliated Programs, all respondents $(n=377)$

\begin{tabular}{|c|c|c|c|c|c|}
\hline \multirow[t]{2}{*}{ Characteristic } & \multicolumn{2}{|c|}{$\begin{array}{l}\text { Ryan } \\
(n=|9|)\end{array}$} & \multicolumn{2}{|c|}{$\begin{array}{l}\text { Non-Ryan } \\
(n=186)\end{array}$} & \multirow[t]{2}{*}{$P$-value } \\
\hline & Mean & SD & Mean & SD & \\
\hline \multirow[t]{2}{*}{ Age } & 29.0 & 2.1 & 28.9 & 2.2 & 0.62 \\
\hline & $\mathbf{N}$ & $\%$ & $\mathbf{N}$ & $\%$ & \\
\hline Race & & & & & 0.29 \\
\hline Black & 9 & 4.7 & 13 & 7.0 & \\
\hline White & 154 & 81.1 & 155 & 83.3 & \\
\hline Others & 27 & 14.2 & 18 & 9.7 & \\
\hline Ethnicity & & & & & 0.06 \\
\hline Hispanic & 14 & 7.4 & 5 & 2.7 & \\
\hline Non-Hispanic & 175 & 92.6 & 179 & 97.3 & \\
\hline Marital status & & & & & 0.89 \\
\hline Married & 87 & 45.5 & 89 & 47.8 & \\
\hline Not married but partnered & 74 & 38.7 & 68 & 36.6 & \\
\hline No partner & 30 & 15.7 & 29 & 15.6 & \\
\hline Respondent/Partner sex & & & & & 0.16 \\
\hline $\begin{array}{l}\text { Female respondent, male } \\
\text { partner }\end{array}$ & 147 & 77.0 & 133 & 71.5 & \\
\hline $\begin{array}{l}\text { Female respondent, female } \\
\text { partner }\end{array}$ & 0 & 0 & 3 & 1.6 & \\
\hline Female respondent, no partner & 31 & 16.2 & 30 & 16.1 & \\
\hline $\begin{array}{l}\text { Male respondent, female } \\
\text { partner }\end{array}$ & 13 & 6.8 & 20 & 10.8 & \\
\hline Current level of training & & & & & 0.26 \\
\hline Postgraduate year I & 51 & 26.7 & 35 & 18.8 & \\
\hline Post graduate year-2 & 52 & 27.2 & 50 & 26.9 & \\
\hline Postgraduate year 3 & 43 & 22.5 & 46 & 24.7 & \\
\hline Postgraduate year 4 & 45 & 23.6 & 55 & 29.6 & \\
\hline Religion & & & & & $<0.01$ \\
\hline Agnostic, atheist, and none & 70 & 36.6 & 36 & 19.4 & \\
\hline Hindu, Islamic, Buddhist, other & 16 & 8.4 & 11 & 5.9 & \\
\hline Catholic & 24 & 12.6 & 49 & 26.3 & \\
\hline Christian, Mormon & 33 & 17.3 & 66 & 35.5 & \\
\hline Jewish & 29 & 15.2 & 8 & 4.3 & \\
\hline Protestant & 19 & 9.9 & 16 & 8.6 & \\
\hline Religion dichotomized & & & & & $<0.01$ \\
\hline Agnostic, atheist, and none & 70 & 36.6 & 36 & 19.4 & \\
\hline Any religion & $12 \mid$ & 63.4 & 150 & 80.6 & \\
\hline $\begin{array}{l}\text { Currently pregnant or } \\
\text { trying to conceive }\end{array}$ & & & & & 0.04 \\
\hline No & 183 & 95.8 & 168 & 90.3 & \\
\hline Yes & 8 & 4.2 & 18 & 9.7 & \\
\hline Current LARC a use & & & & & $<0.01$ \\
\hline No & 55 & 30.1 & 123 & 73.2 & \\
\hline Yes & 128 & 70.0 & 45 & 26.8 & \\
\hline
\end{tabular}

Notes: Column percentages do not always equal 100\% as some survey questions were not answered by the participants.

aLARC including IUDs or implants.

Abbreviations: SD, standard deviation; LARC, long-acting reversible contraception; IUD, intrauterine device; Ryan Pragram, Ryan Residency Training Program.
non-LARC method, and 7.1\% (25/351) reported not using a method. The most common LARC method used was the levonorgestrel IUD (158/173, 91.3\% of LARC users; $158 / 351,45 \%$ of total cohort). The most commonly reported non-LARC method was the combined oral contraceptive pill (94/153, 61.4\% of non-LARC users; 94/351, 26.8\% of total cohort). Table 2 demonstrates the method mix used by respondents.

Demographic comparisons between LARC and nonLARC contraceptive users are presented in Table 3. LARC use was reported by $70.0 \%$ (128/183) of residents affiliated with a Ryan Program and 26.8\% (45/168) by non-Ryan Program residents $(P<0.01)$. When we compared LARC and non-LARC (including no method) users, we found no statistically significant differences in age, race, marital status, or current level of training. The 2 groups differed in response to the most important reason they identified for choosing their contraceptive method (Tables 3 and 4): respondents using LARC reported the effectiveness of the method $(82 / 173$, $47.4 \%)$ and convenience/ease of use $(43 / 173,24.9 \%)$ to be the most important factors. Non-LARC users reported menstrual symptom control, including heavy bleeding, and effectiveness of the method to be the most important factors: $31.5 \%$ (56/178) and $28.1 \%$ (50/178), respectively. After adjusting for differences among the groups, including religion and reason for method of choice, residents in Ryan Programs were found to be 2 times more likely (RR 2.14, 95\% confidence interval 1.63-2.80) to use a LARC method than their non-Ryan counterparts (Table 4).

\section{Discussion}

In this analysis of contraceptive use, we found that approximately half of $\mathrm{Ob} / \mathrm{Gyn}$ residents were using LARC methods,

Table 2 Current contraceptive method use $(\mathrm{N}=35 \mathrm{I})$

\begin{tabular}{lll}
\hline Method & Frequency & \% \\
\hline LARC & $\mathbf{1 7 3}$ & $\mathbf{4 9}$ \\
Levonorgestrel intrauterine device & 158 & 45 \\
Copper intrauterine device & 8 & 2 \\
Subdermal implant & 7 & 2 \\
Non-LARC & $\mathbf{1 5 3}$ & $\mathbf{4 4}$ \\
Depot medroxyprogesterone acetate & 3 & 1 \\
Pills & 94 & 27 \\
Patch & 1 & 0 \\
Ring & 27 & 8 \\
Condoms & 16 & 5 \\
Abstinence & 5 & 1 \\
Sterilization (male or female) & 1 & 0 \\
Other & 6 & 2 \\
No method & $\mathbf{2 5}$ & $\mathbf{7}$ \\
\hline
\end{tabular}

Abbreviation: LARC, long-acting reversible contraception. 
Table 3 Characteristics of study population by use of LARC vs. non-LARC method ( $\mathrm{n}=35 \mathrm{I})$

\begin{tabular}{|c|c|c|c|c|c|}
\hline \multirow[t]{2}{*}{ Characteristic } & \multicolumn{2}{|c|}{$\begin{array}{l}\text { LARC } \\
(n=173)\end{array}$} & \multicolumn{2}{|c|}{$\begin{array}{l}\text { Non-LARC/no } \\
\text { method }(n=\mid 78)\end{array}$} & \multirow[t]{2}{*}{$P$-value } \\
\hline & Mean & SD & Mean & SD & \\
\hline \multirow[t]{2}{*}{ Age } & 29.0 & 2.4 & 28.9 & 1.9 & 0.63 \\
\hline & $\mathbf{N}$ & $\%$ & $\mathbf{N}$ & $\%$ & \\
\hline Race & & & & & 0.45 \\
\hline Black & 8 & 4.6 & 14 & 7.9 & \\
\hline White & 144 & 83.2 & 143 & 80.8 & \\
\hline Others & 21 & 12.2 & 20 & 11.3 & \\
\hline Ethnicity & & & & & 0.44 \\
\hline Hispanic & II & 6.4 & 8 & 4.5 & \\
\hline Non-Hispanic & 161 & 93.6 & 169 & 95.5 & \\
\hline Marital status & & & & & 0.68 \\
\hline Married & 76 & 43.9 & 75 & 42.1 & \\
\hline $\begin{array}{l}\text { Not married but } \\
\text { partnered }\end{array}$ & 71 & 41.1 & 70 & 39.3 & \\
\hline No partner & 26 & 15.0 & 33 & 18.6 & \\
\hline $\begin{array}{l}\text { Current level of } \\
\text { training }\end{array}$ & & & & & 0.47 \\
\hline Postgraduate year I & 47 & 27.1 & 37 & 20.8 & \\
\hline Postgraduate year 2 & 42 & 24.3 & 49 & 27.5 & \\
\hline Postgraduate year 3 & 42 & 24.3 & 41 & 23.0 & \\
\hline Postgraduate year 4 & 42 & 24.3 & 51 & 28.7 & \\
\hline Personal religion & & & & & $<0.01$ \\
\hline $\begin{array}{l}\text { Agnostic, Atheist, and } \\
\text { none }\end{array}$ & 67 & 38.7 & 35 & 19.7 & \\
\hline $\begin{array}{l}\text { Hindu, Islamic, Buddhist, } \\
\text { other }\end{array}$ & 11 & 6.4 & 12 & 6.7 & \\
\hline Catholic & 28 & 16.2 & 42 & 23.6 & \\
\hline Christian, Mormon & 36 & 20.8 & 55 & 30.9 & \\
\hline Jewish & 14 & 8.1 & 20 & 11.2 & \\
\hline Protestant & 17 & 9.8 & 14 & 7.9 & \\
\hline $\begin{array}{l}\text { Personal religion, } \\
\text { dichotomized }\end{array}$ & & & & & $<0.01$ \\
\hline $\begin{array}{l}\text { Agnostic, atheist, and } \\
\text { none }\end{array}$ & 67 & 38.7 & 35 & 19.7 & \\
\hline Any religion & 106 & 61.3 & 143 & 80.3 & \\
\hline $\begin{array}{l}\text { Most important } \\
\text { reason for method } \\
\text { choice }\end{array}$ & & & & & $<0.01$ \\
\hline $\begin{array}{l}\text { Effective pregnancy } \\
\text { prevention }\end{array}$ & 82 & 47.4 & 50 & 28.1 & \\
\hline $\begin{array}{l}\text { Convenient and easy } \\
\text { to use }\end{array}$ & 43 & 24.9 & 41 & 23.1 & \\
\hline Method is long acting & 21 & 12.1 & 2 & 1.1 & \\
\hline $\begin{array}{l}\text { Bleeding, symptom, or } \\
\text { menstrual control }\end{array}$ & 22 & 12.7 & 56 & 31.5 & \\
\hline Others & 5 & 2.9 & 28 & 15.7 & \\
\hline
\end{tabular}

Notes: Column percentages do not always equal 100\% as some survey questions were not answered by the participants.

Abbreviations: SD, standard deviation; LARC, long-acting reversible contraception.

a rate more than 4 times higher than the general population. ${ }^{5}$ This percentage is remarkable, given current IUD and implant use in the US. In addition, residents in Ryan-affiliated training programs were twice as likely to use LARC as residents in non-affiliated programs.
Table 4 Factors associated with current LARC use

\begin{tabular}{|c|c|c|c|}
\hline \multirow{3}{*}{$\begin{array}{l}\text { Factor } \\
\text { Ryan Program }\end{array}$} & \multicolumn{3}{|c|}{ Adjusted model } \\
\hline & \multirow{2}{*}{$\begin{array}{l}\mathbf{R R} \\
2.14\end{array}$} & \multicolumn{2}{|c|}{$95 \% \mathrm{Cl}$} \\
\hline & & 1.63 & 2.80 \\
\hline \multicolumn{4}{|l|}{ Personal religion, dichotomized } \\
\hline \multicolumn{4}{|l|}{ Agnostic, Atheist, and none } \\
\hline All other religions & 0.76 & 0.64 & 0.92 \\
\hline \multicolumn{4}{|l|}{ Most important reasons for method choice } \\
\hline Effective pregnancy prevention & 3.48 & 1.46 & 8.28 \\
\hline Convenient and easy to use & 3.05 & 1.26 & 7.39 \\
\hline Method is long acting & 4.14 & 1.75 & 9.80 \\
\hline Bleeding, symptom, or menstrual control & 1.81 & 0.72 & 4.57 \\
\hline
\end{tabular}

Abbreviations: LARC, long-acting reversible contraception; RR, relative risk; $\mathrm{Cl}$, confidence interval; Ryan Program, Ryan Residency Training Program.

Multiple studies have shown that level of knowledge regarding contraception is an important factor in personal contraceptive method choice. ${ }^{15,16}$ We found an association between exposure to the Ryan Program and LARC use. Residents who are more comfortable with the evidence supporting use of LARC methods may be more comfortable using the method themselves. A survey of family planning providers supports this conclusion and revealed that $42 \%$ of these providers were themselves using a LARC method. ${ }^{15}$ Two additional recent international surveys of female healthcare providers corroborate these findings and one of these studies concluded that personal contraceptive choice influenced contraceptive recommendations to patients. ${ }^{17,18}$

LARC uptake in the US is increasing; however, it is still lower than many developed countries. ${ }^{19}$ Recent reports have shown that use of LARC methods has grown 5 -fold since 2002. ${ }^{4}$ However, the most recent national data indicate that only $11.6 \%$ of women using contraception are using an IUD or implant. ${ }^{5}$

Our study describes the contraceptive use of $\mathrm{Ob} / \mathrm{Gyn}$ residents in the US and evaluates the association of a formalized contraception and abortion curriculum on those method choices. This study is unique in that the respondents are not only highly educated and insured, but are also currently in training programs to become practicing $\mathrm{Ob} /$ Gyns. Having insurance as well as familiarity with current evidence theoretically eliminates two of the most common barriers to increased LARC uptake. When not covered by insurance, LARC is associated with an initial substantial out-of-pocket expense and decreased LARC use. ${ }^{20}$ Although it is possible that some respondents, particularly those training at a religiously affiliated residency programs, may not have contraceptive coverage, we did not specifically ask this question and therefore were unable to control this variable in the analysis. 
Our study had several strengths. Achieving adequate responses to electronic surveys is difficult, with the mean historical response rate being $37 \% .{ }^{21}$ Our survey response rate was $60 \%$, which we believe is sufficiently high to minimize nonresponse bias. ${ }^{22}$ However, given that only $75 \%$ of programs agreed to participate, our effective response rate was lower $(60 \% * 75 \%=45 \%)$. Even with this consideration, we believe this survey to be among the largest contemporary surveys of contraceptive use in US Ob/Gyn residents. Second, although prior studies examined knowledge regarding LARC as well as personal use of LARC in providers across different specialties, our study explored LARC use in Ob/Gyn residents in training, a group that is expected to be knowledgeable regarding all contraceptive methods.

Our study was not without limitations. We attempted to sample a geographically diverse population of both Ryan and non-Ryan Programs. However, we did not sample every US $\mathrm{Ob} / \mathrm{Gyn}$ residency program and, for efficiency, we did not invite programs with a small number of residents. Yet we attempted to minimize sample bias by stratifying programs by geographic region and Ryan affiliation. Second, as a cross-sectional survey, we could not establish causality. It is possible, for example, that residents who selected a residency with a Ryan Program are more likely to use LARC regardless of the educational experience of the specific training program. We also did not include timing of contraceptive initiation in our analysis; thus, we could not establish temporal sequence. In addition, students with a greater interest in family planning may be more likely to choose a residency program with Ryan training. Lastly, as mentioned earlier, there may be residual confounding that we were unable to control in our analysis such as contraceptive insurance coverage and resident choice of training program.

While our population is not representative of the national population, we feel we have demonstrated that, as in the Contraceptive CHOICE project, when knowledge, access, and financial barriers to contraception are removed, women are more likely to choose the most effective contraceptive methods. ${ }^{7,8,15}$ Our study suggests that exposure to formalized and evidence-based contraceptive and abortion curriculum may result in a higher uptake of these methods.

\section{Acknowledgments}

This research was supported in part by the Washington University Institute of Clinical and Translational Sciences National Center for Research Resources grant UL1 RR024992 from the National Center for Advancing Translational Sciences and the Eunice Kennedy Shriver National Institute of Child Health \& Human Development of the National Institutes of Health under award number T32HD055172. The REDCap program was employed, which is supported by Clinical and Translational Science Award Grant UL1 TR000448 and Siteman Comprehensive Cancer Center and NCI Cancer Center Support Grant P30 CA091842.

\section{Disclosure}

Dr Peipert receives research funding/support from Bayer Healthcare Pharmaceuticals, TEVA Pharmaceuticals, and Merck \& Co, Inc. He has also served on advisory boards of TEVA Pharmaceuticals and Perrigo. The other authors report no conflicts of interest in this work.

\section{References}

1. Winner B, Peipert JF, Zhao Q, et al. Effectiveness of long-acting reversible contraception. N Engl J Med. 2012;266(21):1998-2007.

2. Stern LF, Simons HR, Kohn JE, Debevec EJ, Morfesis JM, Patel AA. Differences in contraceptive use between family planning providers and the U.S. population: results of a nationwide survey. Contraception. 2015;91(6):464-469.

3. Finer LB, Jerman J, Kavanaugh ML. Changes in use of long-acting contraceptive methods in the United States, 2007-2009. Fertil Steril. 2012;98(4):893-897.

4. Branum AM, Jones J. Trends in Long-acting Reversible Contraception Use Among U.S. Women Aged 15-44. NCHS Data Brief, No 188. Hyattsville, MD: National Center for Health Statistics; 2015.

5. Guttmacher Institute. Contraceptive Use in the United States. 2015. Available from: https://www.guttmacher.org/fact-sheet/contraceptiveuse-united-states. Accessed September 13, 2014.

6. Secura GM, Allsworth JE, Madden T, Mullersman JL, Peipert JF. The contraceptive CHOICE project: Reducing barriers to long-acting reversible contraception. Am J Obstet Gynecol. 2010;203(2):115.e1-e7.

7. Peipert JF, Madden T, Allsworth JE, Secura GM. Preventing unintended pregnancies by providing no cost contraception. Obstet Gynecol. 2012;120(6):1291-1297.

8. McNicholas C, Madden T, Secura GM, Peipert JF. The contraceptive CHOICE project round up: what we did and what we learned. Clin Obstet Gynecol. 2014;57(4):635-643.

9. Secura G. Long-acting reversible contraception: a practical solution to reduce unintended pregnancy. Minerva Ginecol. 2013;65(3): 271-277.

10. Steinauer JE, Turk JK, Fulton MC, Simonson KH, Landy Y. The benefits of family planning training: a 10-year review of the Ryan Residency Training Program. Contraception. 2013;88(2):275-280.

11. Accreditation Council for Graduate Medical Education. ACGME Program Requirements for Graduate Medical Education in Obstetrics and Gynecology. Available from: www.acgme.org/Portals/0/PFAssets/ ProgramRequirements/220_obstetrics_and_gynecology_2016.pdf. Accessed September 13, 2014.

12. ACOG. The American Congress of Obstetricians and Gynecologists. Available from: www.acog.org. Accessed September 13, 2014.

13. The Kenneth J Ryan Residency Training Program in Abortion and Family Planning. Available from: www.ryanprogram.org. Accessed October 25, 2016.

14. Harris PA, Taylor R, Thielke R, Payne J, Gonzalez N, Conde JG. Research electronic data capture (REDCap) - a metadata-driven methodology and workflow process for providing translational research informatics support. J Biomed Inform. 2009;42(2):377-381.

15. Stern L, Debevec E, Devaskar S, Morfesis J, Patel A. Differences in contraceptive use between family planning providers and the general population. Obstet Gynecol. 2014;123 (Suppl 1):14S-5S.

16. Harper C, Thompson K, Stratton L, Goodman S, Dickson A, Speidel J. Knowledge of contraceptive effectiveness among young women is associated with LARC use. Contraception. 2012;86(3):322. 
17. Lete I, Pérez-Campos E. Differences in contraceptive use between Spanish female healthcare providers and Spanish women in the general population aged 23 to 49 years: the HABITS Study. Eur J Contracept Reprod Health Care. 2014;19(3):161-168.

18. Gemzell-Danielsson K, Cho S, Inki P, Mansour D, Reid R, Bahamondes L. Use of contraceptive methods and contraceptive recommendations among health care providers actively involved in contraceptive counseling -- results of an international survey in 10 countries. Contraception 2012;86:631-638.
19. Clifton D, Kaneda T, Ashford L. Family Planning Worldwide 2008 Data Sheet. Washington, DC: Population Reference Bureau; 2008:15.

20. Bearak JM, Finer LB, Jerman J, Kavanaugh ML. Changes in out-of-pocket costs for hormonal IUDs after implementation of the Affordable Care Act: an analysis of insurance benefit inquiries. Contraception. 2016;93(2):139-144.

21. Sheehan K. E-mail survey response rates: a review. J Comput Mediat Commun. 2001;6(2):0.

22. Groves RM, Peytcheva E. The impact of nonresponse rates on non response bias: a meta-analysis. Public Opin Q. 2008;72(2):167-189.
Open Access Journal of Contraception

\section{Publish your work in this journal}

Open Access Journal of Contraception is an international, peerreviewed, open access, online journal, publishing original research, reports, reviews and commentaries on all areas of contraception. In addition to clinical research, demographics and health-related aspects, the journal welcomes new findings in animal and preclinical studies

\section{Dovepress}

relating to understanding the biological mechanisms and practical development of new contraceptive agents. The manuscript management system is completely online and includes a very quick and fair peer-review system. Visit http://www.dovepress.com/testimonials.php to read real quotes from published authors.

Submit your manuscript here: https://www.dovepress.com/open-access-journal-of-contraception-journal 